\title{
The Physical Education Teaching in Colleges from the Perspective of Lifelong Sports
}

\author{
Sun Fenglin \\ Department of Physical Education, Beijing WuZi University, Beijing, China \\ sunfenglinna@sina.com
}

\begin{abstract}
This article discusses the necessity of combining education and lifelong physical education in colleges, and sets out the theoretical basis of the connection between the physical education in colleges and lifelong physical education. Based on that, the paper also analyzes the problems on teaching philosophy, curriculum, evaluation of teaching and teaching methods of college sports. In addition, some detailed suggestions are put forward for improvement.

Index Terms - Physical education, lifelong sports, curriculum, evaluation
\end{abstract}

\section{Introduction}

With the quickening pace of China's socialist modernization, people's living standard has greatly improved. However, the physical conditions of college students in China are on a descending trend, and college students do not pay attention to sports exercises, and have less lifelong sports consciousness.

A famous educator of France proposed the theory of lifelong education in the 1960 of the 20th century. In 1970, he pointed out the concept of lifelong education. If the role of physical education in the school is ignored, the physical activities of students do not exist in the adult stage. If this phase is called the school sports, then it becomes the episode sport in teaching. He made clear the relationship between education and sport, also reveals the relationship between school physical education and lifelong physical education in depth. In the International Charter of sport it is regulated. Sport is a comprehensive education system which is necessary for lifelong learning. There must be a global democratization of life-long education system to ensure that the practice of physical activities and sport runs through everyone's life. The decline of the health of the students has become a very serious problem currently. The middle and long distance races have been cancelled in some school sports meetings in colleges. We need to consider the question about the students' physical exercises in their life seriously.

\section{The Theoretical Basis of Cohesion between College Sports and Lifelong Sports}

Lifelong sports consciousness, to a great extent, depends on the Physical Exercises education for the students when they are in colleges. At that time, the pressure of college entrance examination has been over, and they can do more physical exercises based on their interests and wishes. Some theories can explain the cohesive relationship between college sports and lifelong sports.

\section{A. Theory of Motivation}

Motivation refers to the psychological motivations or internal driving forces to promote personal activities. We can classify motivations according to the features of interest: (1) direct motivation: it refers to the activity itself, taking direct interest as the foundation. (2) indirect motivation: it refers to the result based on the indirect interest. For example, if a person loves to play basketball, and can get fun from it, this is because he is driven by the direct motivation, while a twelveminute running test is mostly caused by indirect motivation. A person is often influenced by the direct motivation. General physical activity is driven by these two kinds of motivation. The body need is an unbalanced state, which reflects the necessity and some objective requirements. When the need is not being met it will push people to meet the needs of the objectives, thereby generate activities motivation. It is the basic motivation of the individual activities.

The interest and motivation of the students' lifelong sports can be cultivated by using the motivation theory. The idea of lifelong sports education can be strengthened by lifelong physical training motivation. The lifelong sports motivation is the key link which goes through from the lifelong sports consciousness and lifelong sports behavior. This can cause and maintain life-long sports practice. We can guide lifelong sports from the following aspects: The first is the need of human development. The second is the need for lifelong education. The third is the need of social development and the way of life. The fourth is the need to improve and develop the individuality.

\section{B. Reception theory}

Reception theory was born in twentieth Century six, seventy time, originally is a literature theory and criticism sect, founded by Konstanz school. It is a focus on works and writers in the past the traditional literary theories, literature writers, works and readers in the three times, and focuses on the receiving consciousness of the readers and creating in the position and role of the literary value .

The cohesion between the school physical education and lifelong physical education actually is a kind of cultural acceptance. In the cultural forms, the school sports have a natural connection with the lifelong physical education. For cohesive pursuit, the core is to make the students receive sports. Sports not only help students understand what knowledge are learned to accept, but also attract them in the physical activities in the process by reflection, selection, 
integration within the link, eventually form the main relatively stable consciousness, and transform it into a pattern of behavior.

The main features of sports reception is a kind of emotional behavior to accept. In the course of the sports of reception theory, the rational value of participation and irrational emotional participation go throughout the entire process. In the process of acceptance, sports have become an objective of value, and the students are treated as the subject of acceptance. Emotion is an indispensable factor, whose main function is to strengthen the reception and influence acceptance intention and selection criteria. If you want to join the school physical education with the lifelong physical theory, the sports value of perception, understanding, and emotional experience must be paid more attention.

\section{Problems Existing in P.E. Teaching in Colleges}

Although the PE teaching is important for college students, and it has adopted some advanced teaching theories and teaching facilities, there are still some problems existing in the P.E. teaching processes in colleges. Realizing these problems will contribute to the improvement of P.E. teaching in colleges.

\section{A. Teaching Philosophy}

A lot of College PE teachers tend to focus only on the sports technique teaching, they do not pay much attention to the cultivation of physical abilities; they only focus on the knowledge, do not pay attention to cultivate students' sports habits. These behaviors have hindered the formation of lifelong sports concept for the students.

\section{B. Curriculum}

Firstly, the curriculum of the athletics is monotonous. Sport is used to cultivate the elite talent, but the purpose of the school sports is to do exercises. Competitive sports and the exercises of the ordinary students are different, and it is easy to make some students with poor motor skills feel depressed by the teaching of sports, and the ordinary students are the key objects of lifelong physical education. Secondly, it is no difference in teaching content among the universities and schools. From primary school to secondary school and to colleges or universities the same content of PE teaching are taught, so the students are prone to be tired of that.

\section{Teaching Methods}

Teachers tend to use the traditional teaching method in the teaching material, so that students are not interested in it. This is not conducive to the students to master the movement technology and sports knowledge, and it is not conducive to motivate students to participate in classroom teaching. Therefore, it is difficult to achieve the expected teaching effect. Not focusing on the induction, the teaching methods, more often than not, ignore the teaching methods which are deductive ones, and stifle students' personality, creativity. Not to stimulate the motivation, ability of the students, the teaching is not conducive to the lifelong sports consciousness and habits.

\section{Teaching Evaluation}

First, the practice of the one-side pursuit of comprehensive evaluation index is not conducive to the formation of the correct quality concept. The evaluation system has become a fixed frame, and teachers must teach according to the unified model. Thus, it is not conducive to show the teacher's creativity and the students' personality.

Second, the emphasis on quantitative evaluation index of one-sidedness leads to the emphasis on quantitative evaluation results, which emphasize operation and comparability. The meaningful things for teaching are often overlooked, such as the formation of sports values, cultivating a lifelong sports consciousness and sports abilities.

Third, the evaluation model is monotonous, and is not conducive to the evaluation function. Our country sports evaluation is mostly carried out for the "establishment of the indicator system and weight distribution and quantitative evaluation calculation results" mode, which will not meet the students' diversified needs of multi-level. The evaluation should be advanced, and it needs to guide physical education to meet the lifelong education needs, the need of social development, and the need of the teaching evaluation.

\section{Measures for Improvement of College P.E. Teaching}

A. Adjusting the teaching objectives of physical education

College physical education is an important part of the development of sports in our country. It can be used to rich after-school life, and to take the campus spiritual civilization construction. It is the key to the implementation of lifelong sports, as it is conducive to the all-round development of students' physical quality and physical fitness and cultivating the students' noble character and strong will. In addition, it is also conducive to the further education in all aspects, and to promote their physical and mental development.

College physical education is essential to solve the problem of consciousness of students' lifelong physical education, and it is no longer considered as the only canter during school, but is understood as the continuum of lifelong sports exercise, during the period of schooling sports should serve the lifelong sports. Therefore, the goal of college physical education should be determined to benefit from the life of students as the starting point, considering the age, gender, school students physiological, psychological, mental and physical aspects, cultivating the students' lifelong physical training consciousness, habits and abilities.

\section{B. Updating education ideas and developing students' lifelong habits, attitudes and abilities}

The changes are from the focus only on short-term benefits to pursue long-term benefits, for the school physical education and lifelong physical education are cohesively integrated in the same direction. In practice, we dare to break 
the old ideas, because the old ideas are probably bound to cover the most stubborn aspects.

First, school sports habit is the key to lifelong sports. From a physiological point of view, the habit is a conditioned reflex, which is a regular physical exercise (repeated stimulation ) gradually formed. In the course of the physical education and sports practice we should pay attention to the habits, and also guide the students to establish a scientific fitness programs, namely the exercise prescription.

Second, the student' sports ability is the important guarantee of lifelong physical education.

The core function can be reflected in two aspects, the complex physical function and psychological function. Physical ability is a special ability, which refers to a kind of personality that is composed of individual sports wisdom, sports knowledge, technology, skills, physical and mental quality. It includes sports cognition, sports ability, viewing capabilities, evaluation ability, judgment ability, organization ability, and innovation ability. Cultivating the sports ability plays an important role for the lifelong sports. It promotes the habit of lifelong physical education, motivation of implementation, which is the embodiment of quality education in the stage of school sports, school sports and lifelong physical connection.

\section{Setting the Curriculum to the students' taste}

In order to add the content of physical education and to improve the learning of their students, we should increase the content of elective courses based on the syllabus of physical education. This can enhance the enthusiasm of the students to master physical exercises, contents and more rich comprehensive methods, and lay the foundation for lifelong sports to increase the variety and quantity of non-competitive projects, such as roller skating, shuttlecock, fitness, rock climbing, bowling, ballroom dancing, climbing, hiking, orienteering.

\section{Enriching the Teaching Methods}

First, the comprehensive utilization of inquiry method, discovery method, game method, discussion method, game method need to be adopted to stimulate the learning and the passion of the students, to improve the students' subjectivity, creativity, and to cultivate students' interests in sports.

Second, we can use modern multi-media technologies. These methods can make the teaching content more vivid and improve the teaching initiative, which can greatly mobilize the enthusiasm of students. The application of computer and multimedia in physical education teaching can cultivate students' initiative to acquire knowledge and the ability to use knowledge and also enrich the teaching means.

\section{E. Improving the Evaluation Model}

The enthusiasm can be mobilized by the rational use of examination on life-long sports. Physical examination is an important part of physical education teaching in colleges. The examination can help teachers understand their teaching effectiveness, make them easy to identify deficiencies. It can also develop the advantage to improve teaching, promote students' initiative to consciously exercise. You can use standard elasticity of examination, pay attention to students' sports habit, attitude, and technical difference of desalination students to replace the summative evaluation to process evaluation, to stimulate the students' enthusiasm of exercise.

\section{F. Utilizing rich resources of Curriculum}

First, use and develop the human resources of sports. Teachers should be trained, for instance, to hire outside scholars, professor, high-level coaches to do the theoretical training.

Second, sports facilities can be used in multi-channel. It is reasonable to develop and use the good units of the resources, such as swimming, skating ice stadium, gymnasium.

Third, the development of sports information resources is rational. We can establish the teaching facilities, and widen the channel of information resources, which is connected with the radio, television, newspapers and other media.

Fourth, we should strengthen the construction of campus sports culture. We should organize the sports department and hold the large-scale sports competitions, sports knowledge contest organization and develop traditional events such as Beijing University, Tsinghua University Rowing .

\section{Conclusion}

Based on the theories of lifelong sports, it is necessary to combine the physical education and lifelong education in colleges. There are solid foundations of the connection between the physical education in colleges and lifelong physical education. Some suggestions or measures have been put forward for improvement, which are adjusting the teaching objectives of physical education, updating education ideas and developing students' lifelong habits, attitudes and abilities, setting the curriculum to the students' taste, enriching the Teaching Methods, utilizing rich resources of Curriculum, and utilizing rich resources of curriculum.

\section{References}

[1] Wang Zeshan, “ a lifelong study of sports”, Journal of Beijing Sport University, vol. 8, no. 2, pp. 23-25, March 2001.

[2] Lin Song, "lifelong physical education and sports interest, sports ability", Journal of physical education, vol. 4, no. 4, pp. 15-25, March 2005.

[3] Zhang Yi, "analysis of secondary school students sports culture area difference", Journal of Institute of Shenyang, vol. 7, no. 3, pp.56-58, May 2008.

[4] Qi Yi, "on the teaching reform of physical education from the social process", Journal of Beijing Sport University, vol. 9, no. 1, pp.46-56, Feb 2009.

[5] Maxwell, J. A. (1996). Qualitative research design: An interactive approach. Sage Publications. Thousand Oaks: CA .McArthur, L. H. \& Raedeke, T. D. (2008). Race and sex differences in college student physical activity correlates. American Journal of Health Behavior. 4(1),80-89.

[6] Merriam, S. B. (2002). Qualitative research in practice: Examples for discussion and analysis. Jossey-Bass. H. Simpson, Dumb Robots, 3rd ed., Springfield: UOS Press, 2004, pp.6-9.

[7] M. King and B. Zhu, "Gaming strategies," in Path Planning to the West, vol. II, S. Tang and M. King, Eds. Xian: Jiaoda Press, 1998, pp. 158-176.

[8] Mills, G. (2003). Action research: A guide for the teacher researcher (2nd ed.). Upper Saddle River, NJ: Pearson Education. 
[9] NASPE - National Association for Sport and Physical Education \& American Heart Association. (2006). 2006 Shape of the Nation Report: Status of Physical Education in the USA. Reston, VA: National Association for Sport and Physical Education

[10] Phillips, K. R., Revels, M., \& Ujamaa, D. (2010). Contribution of the school environment to physical fitness in children and youth. Journal of Physical Activity and Health.7, 333-342.
[11] Sidman, C. L., D Abundo, M. L., \& Hritz, N. (2009) Exercise selfefficacy and perceived wellness among college students in a basic studies course. International Electronic Journal of Health Education. 12:162-174.

[12] Sisson, S. B., (2005). College students understanding of physical activity. American Journal of Health Studies. 34(2), 1-2. 